\title{
Priming and Multiple Memory Systems: Perceptual Mechanisms of Implicit Memory
}

\section{Citation}

Schacter, Daniel L. 1992. Priming and multiple memory systems: Perceptual mechanisms of implicit memory. Journal of Cognitive Neuroscience 4(3): 244-256.

\section{Published Version}

doi:10.1162/jocn.1992.4.3.244

\section{Permanent link}

http://nrs.harvard.edu/urn-3:HUL.InstRepos:3627272

\section{Terms of Use}

This article was downloaded from Harvard University's DASH repository, and is made available under the terms and conditions applicable to Other Posted Material, as set forth at http:// nrs.harvard.edu/urn-3:HUL.InstRepos:dash.current.terms-of-use\#LAA

\section{Share Your Story}

The Harvard community has made this article openly available.

Please share how this access benefits you. Submit a story.

Accessibility 


\title{
Priming and Multiple Memory Systems: Perceptual Mechanisms of Implicit Memory
}

\author{
Daniel L. Schacter \\ Department of Psychology \\ Harvard University
}

\begin{abstract}
Research examining the relation between explicit and implicit forms of memory has generated a great deal of evidence concerning the issue of multiple memory systems. This article focuses on an extensively studied implicit memory phenomenon, known as direct or repetition priming, and examines the hypothesis that priming effects on various tasks reflect the operation of a perceptual representation system (PRS)-a class
\end{abstract}

of cortically based subsystems that operate at a presemantic level and support nonconscious expressions of memory. Three PRS subsystems are examined: visual word form, structural description, and auditory word form. Pertinent cognitive, neuropsychological, and neurobiological evidence is reviewed, alternative classificatory schemes are discussed, and important conceptual and terminological issues are considered.

\section{INTRODUCTION}

During the past 25 years, questions concerning the nature and number of memory systems have been at the forefront of cognitive, neuropsychological, and neurobiological research (for historical overview, see Polster, Nadel, \& Schacter, 1991). In the study of human memory, a key line of evidence for multiple memory systems has been provided by investigations concerned with the descriptive distinction between explicit and implicit forms of memory (Graf \& Schacter, 1985; Schacter, 1987). Explicit memory refers to intentional or conscious recollection of prior experiences, as assessed in the laboratory by traditional tests of recall or recognition; implicit memory, by contrast, refers to changes in performance or behavior that are produced by prior experiences on tests that do not require any intentional or conscious recollection of those experiences. The distinction between explicit and implicit memory is similar to distinctions between memory with awareness vs. memory without awareness (Jacoby \& Witherspoon, 1982), declarative memory vs. nondeclarative memory (Squire, 1992), and direct memory vs. indirect memory (Johnson \& Hasher, 1987). However, these distinctions are used less frequently in the literature than is the explicit/implicit distinction, and there are various reasons to prefer the explicitimplicit contrast over alternative terms (Roediger, 1990).

The explicit/implicit distinction is a descriptive one that contrasts two different ways in which memory for previous experience can be expressed; it does not refer to, or necessarily imply the existence of, distinct underlying

memory systems. However, interest in the relation between explicit and implicit forms of memory has been sparked by demonstrations of striking dissociations between the two that do indeed suggest that different underlying systems are involved in explicit and implicit memory, respectively. Thus, for example, it has been known for many years that amnesic patients exhibit robust and sometimes normal learning of various perceptual, motor, and cognitive skills despite impaired or absent explicit memory for having acquired them (e.g., Cohen \& Squire, 1980; Milner, Corkin, \& Teuber, 1968). Amnesic patients can also exhibit classical conditioning effects despite poor explicit memory (Daum, Channon, \& Canavar, 1989; Weiskrantz \& Warrington, 1979), and acquire knowledge needed to perform complex computer-related tasks despite the absence of any recollection for having previously performed the tasks (Glisky, Schacter, \& Tulving, 1986; Glisky \& Schacter, 1987, 1988, 1989).

Perhaps the most intensively studied form of implicit memory has come to be known as repetition or direct priming: the facilitated identification of perceptual objects from reduced cues as a consequence of a specific prior exposure to an object (e.g., Tulving \& Schacter, 1990). Priming can be thought of as a form of implicit memory in the sense that it can occur independently of any conscious or explicit recollection of a previous encounter with a stimulus. Thus, amnesic patients can show entirely normal priming as a consequence of a recent encounter with a word or object, despite impaired or even absent explicit memory for the word or object; and studies of nonamnesic, normal subjects have shown that

Journal of Cognitive Neuroscience Volume 4, Number 3 
various experimental manipulations affect priming and explicit memory in different and even opposite ways (for reviews, see Richardson-Klavehn \& Bjork, 1988; Roediger, 1990; Schacter, 1987; Schacter, Chiu, \& Ochsner, 1993; Shimamura, 1986). These and other observations indicate that the kind of information about a recently encountered word or object that supports priming is quite different from the kind of information that supports explicit recollection for an encounter with the word or object. Moreover, priming has also been dissociated from skill learning: studies of dementia indicate that patients with Alzheimer's disease show impaired priming and intact motor skill learning, whereas patients with Huntington's disease show the opposite pattern (e.g., Butters, Heindel, \& Salmon, 1990). A number of investigators have argued further that priming is the expression of a neurocognitive system that differs functionally and neuroanatomically from the neurocognitive system that supports explicit remembering and skill learning, respectively (cf., Cohen, 1984; Schacter, 1985, 1990; Butters et al., 1990; Squire, 1987, 1992; Tulving, 1985; Tulving \& Schacter, 1990).

This article examines in some detail one such proposal, namely, that priming reflects, to a very large extent, the operations of a perceptual representation system (PRS) that can function independently of the episodic or declarative memory system that supports explicit memory (Schacter, 1990, 1992; Tulving \& Schacter, 1990). PRS refers to a class of domain-specific subsystems, based in cortical regions, that process and represent information about the form and structure, but not the meaning and other associative properties, of words and objects. This article will focus on delineating and evaluating characteristics of, and evidence for, three PRS subsystems: visual word form, structural description, and auditory word form. Although they probably do not constitute an exhaustive list of PRS subsystems, various kinds of evidence about them is available, including data from priming studies. Each of the subsystems differs from the others in several ways, but all share common features: they operate at a presemantic level, that is, at a level of processing that does not involve access to the meanings of words or objects, and they are involved in nonconscious expressions of memory for previous experiences. After discussing pertinent issues and results at some length, I will conclude by considering briefly alternative conceptualizations of PRS subsystems and the relation between perceptual and conceptual forms of priming.

\section{PRS SUBSYSTEMS AND PRIMING}

\section{Visual Word Form System}

The term "visual word form system" was first used by Warrington and Shallice (1980) in the context of their research on patients suffering from a type of reading impairment known as letter-by-letter reading. Warrington and Shallice (1980) proposed that the deficit in at least some of these patients could be attributed to the breakdown of a system that represents information about the visual and orthographic form of words. Evidence that such a system operates at a presemantic level is provided by studies that have focused on brain-damaged patients who maintain relatively intact abilities to read words yet exhibit little or no understanding of them (cf. Sartori, Masterson, \& Job, 1987; Schwartz, Saffran, \& Marin, 1980). Importantly, such patients can read words with irregular spellings, thereby indicating that they can gain access to the representations in the word form system (see Schacter, 1990, for further elaboration). Data from neuroimaging studies using positron emission tomography (PET) suggest that the visual form system is based in regions of extrastriate occipital cortex and is neuroanatomically distinct from brain regions subserving semantic processing (e.g., Petersen et al., 1989).

Several lines of evidence have led to the proposal that the visual word form system subserves priming effects on so-called data driven or perceptually based implicit memory tasks, such as stem or fragment completion, where subjects provide the first word that comes to mind in response to three-letter stems or graphemic fragments, and perceptual or word identification, where subjects attempt to identify briefly presented words. One such line of evidence is that amnesic patients show normal priming of familiar words and word pairs on completion, identification, and similar tasks (cf. Cermak et al., 1985; Graf, Squire, \& Mandler, 1984; Moscovitch, 1982; Schacter, 1985; Shimamura \& Squire, 1984; Tulving, Hayman, \& Macdonald, 1991; Warrington \& Weiskrantz, 1974). These results are consistent with the proposal that visual word priming is mediated by a perceptual system based in posterior cortical regions, because the critical sites of brain damage in amnesic patients typically involve the limbic system and medial temporal lobe structures; posterior cortex is spared in the amnesic syndrome (e.g., Rozin, 1976; Scoville \& Milner, 1957; Squire, 1992; Weiskrantz, 1985).

Further evidence from the study of amnesia that bears on this idea has been provided by studies that have examined whether amnesic patients show intact priming of novel word forms-that is, nonwords (e.g., numdy) that do not have preexisting memory representations. Such effects, which have been shown in normal subjects (e.g., Feustel, Shffrin, \& Salasoo, 1983; Rueckl, 1990), provide evidence against the idea that priming is mediated simply by the activation of preexisting representations, and instead suggest the creation of a novel perceptual representation by the word form system (Schacter, 1990). Accordingly, if priming of verbal items in amnesic patients is indeed mediated by an intact word form system, such patients should show priming for nonwords as well as familiar words. Although several studies have reported impaired or absent priming of nonwords in some amnesic patients (i.e., Korsakoff patients and demented subjects; cf. Cermak et al., 1985; Diamond \& 
Rozin, 1984; Smith \& Oscar-Berman, 1990), recent research has provided clear evidence that non-Korsakoff amnesics, and even some Korsakoff patients, can show normal or near-normal priming of nonwords under appropriate experimental conditions (cf. Cermak, Verfaellie, Milberg, Letourneau, \& Blackford, 1991; Gabrieli \& Keane, 1988; Gordon, 1988; Haist, Musen, \& Squire, 1991; Musen \& Squire, 1991; for detailed review, see Bowers \& Schacter, 1992). Thus, the weight of evidence is consistent with the proposition that a spared visual word form system supports priming in amnesic patients.

A second line of evidence that bears on the word form system hypothesis has been provided by experiments examining the effects of semantic vs. nonsemantic study tasks on priming and explicit memory. It has been known since the initiation of research in the levels of processing framework during the 1970s that explicit recall and recognition of a list of target words is much higher following semantic study tasks (e.g., judging the meaning of a word) than nonsemantic study tasks (e.g., counting the number of vowels and consonants in a word; see Craik \& Tulving, 1975). Many studies that have been done since have shown that the same manipulations have little or no effect on priming in such data-driven implicit tests as stem completion (Bowers \& Schacter, 1990; Graf \& Mandler, 1984), fragment completion (Roediger, Weldon, Stadler, \& Riegler, 1992), and perceptual identification (Jacoby \& Dallas, 1981).

The foregoing findings are important because they provide support for the idea that priming is a presemantic phenomenon: if visual word priming depends on a form-based system that does not represent a word's meaning, then it makes sense that semantic study tasks that improve explicit memory do not confer the same benefit on priming. It is therefore worth noting that conditions do exist in which the magnitude of visual word priming is increased significantly by semantic study processing relative to nonsemantic study processing (e.g., Bowers \& Schacter, 1990). However, the results from Bowers and Schacter's experiments suggest strongly that when such effects are observed, they can be attributed to the use of explicit memory strategies by subjects who have "caught on" concerning the relation between the implicit task and the study list. Through the use of a postexperimental questionnaire, Bowers and Schacter determined that subjects who exhibited awareness of the relation between the completion test and the study list showed higher completion rates following semantic than nonsemantic study tasks, whereas subjects who remained unaware of the study-test relation showed equivalent priming following the two study tasks.

A third line of evidence bearing on the nature of the system that subserves visual word priming comes from experiments in which perceptual attributes of target items are changed between study and test. The argument here is that if a visually based system plays a major role in priming, then the magnitude of the effect should be reduced when relevant perceptual attributes are changed between study and test. Various manipulations have been used to evaluate this proposal, and a range of experimental outcomes has been observed, including findings that study-to-test changes in perceptual attributes of target items either reduce or eliminate priming (for review and discussion, see Kirsner, Dunn, \& Standen, 1989; Roediger, Weldon, \& Challis, 1989; Schacter, 1990; Schacter, Chiu, \& Ochsner, 1993). For the present purposes, we focus on the theoretical implications of results from two types of stimulus transformations: (1) modality shifts and (2) changes in the format of target words.

Experiments that have examined effects of modality shifts (i.e., target words are presented auditorily and tested visually) have yielded a relatively consistent pattern of results: priming on completion, identification, and similar tasks is always reduced, and sometimes eliminated, by study-test modality shifts (cf. Graf, Shimamura, \& Squire, 1985; Jacoby \& Dallas, 1981; Clarke \& Morton, 1983; Kirsner \& Smith, 1974; Morton, 1979; Roediger \& Blaxton, 1987). The observed reduction in priming as a consequence of modality shift supports the visual word form system hypothesis. However, the fact that significant cross-modal priming is typically observed, particularly with stem- and fragment-completion tests, suggests that word priming is not based entirely on visual/perceptual processes, a point that will be elaborated on later.

The question of whether visual word priming is affected by study-test changes in the specific format of target items (e.g., typefont, upper/lower case) is of great interest theoretically: If priming is reduced or eliminated by alterations in perceptual format, we have evidence that the system underlying visual word priming computes highly specific perceptual representations of the particular word tokens encountered on a study list; if priming is unaffected by such changes, we have evidence that the system operates at a more abstract level. Moreover, comparative analysis of which perceptual features do and do not impair priming when changed between study and test could provide rather precise information concerning the representational properties of the system underlying priming. A great deal of experimental effort has been devoted to this issue, and has yielded a rather mixed pattern of results. On the one hand, a number of studies have provided evidence that transformations of typefont, case, and orthographic structure can have a significant impact on priming (e.g., Gardiner, 1988; Jacoby \& Hayman, 1987; Hayman \& Tulving, 1989; Roediger \& Blaxton, 1987; Scarborough, Cortese, \& Scarborough, 1977; Whittlesea, 1990). On the other hand, however, other studies have failed to obtain effects of similar manipulations (e.g., Carr, Brown, \& Charambolous, 1989; Clarke \& Morton, 1983; Tardif \& Craik, 1989).

Although some of the conflicting results may be attributable to subtle aspects of experimental procedures (cf. Carr et al., 1989; Whittlesea, 1990), recent studies have helped to clarify matters by elucidating, within the same 
experimental situation, conditions under which study-totest transformation of perceptual features do and do not impair priming. Thus, Graf and Ryan (1990) found that study-to-test changes in typefont reduced priming on a word identification test when the study task required subjects to focus on perceptual features of words, but not when the study task focused on word meaning (cf. Jacoby, Levy, \& Steinbach, 1992). Marsolek, Kosslyn, and Squire (1992) found that changing case of target words between study and test reduced stem completion priming when test stems were presented to the right hemisphere (via the left visual field) but not when test stems were presented to the left hemisphere (via the right visual field).

These findings indicate that a visual encounter with a word does not necessarily or inevitably create a highly specific and novel of representation of it in the word form system, but also indicate that specific perceptual representations are created under appropriate conditions. The Graf and Ryan (1990) data suggest that the system creates novel perceptual representations only when initial processing focuses on visual characteristics of a word, and perhaps only when unusual typefonts are encountered. The Marsolek et al. (1992) data suggest that this effect may depend on right hemisphere involvement - that is, the right hemisphere may constitute the substrate of the novel perceptual representations that produce format-specific priming effects. Marsolek et al. have suggested further that it is necessary to fractionate the word form system into two further subsystems: a left hemisphere subsystem that computes abstract word form representations (i.e., it produces one output for many inputs) and a right hemisphere subsystem that computes perceptually specific word form representations (i.e., it produces a single output for a particular input). They reasoned that these two computations are functionally incompatible (Sherry \& Schacter, 1987)-a system designed to perform one would have difficulty carrying out the other-and hence must be performed by different subsystems. We will return to this point later in the paper.

\section{Structural Description System}

The term structural description refers to a representation of relations among parts of an object that specifies the global form and structure of the object (cf. Sutherland, 1968; Winston, 1975). Several investigators have argued that structural descriptions are computed by a specific brain system - termed the structural description system by Riddoch and Humphreys (1987)-that does not handle semantic-level information about the associative and functional properties of objects (cf. Kosslyn, Flynn, Amsterdam, \& Wang, 1990; Riddoch \& Humphreys, 1987; Warrington, 1975, 1982). We (e.g., Schacter, 1990, 1992; Schacter, Cooper, \& Delaney, 1990; Tulving \& Schacter, 1990) have suggested that the structural description sys- tem can be viewed as a PRS subsystem that is involved in various priming effects that have been observed in the domain of visual object processing. As with the visual word form system, evidence that the structural description system operates at a presemantic level has been provided in the first instance by neuropsychological studies of brain-damaged patients. Specifically, a number of investigators have described patients who have severe deficits in gaining access to semantic information about visual objects, but exhibit relatively intact access to perceptual/structural knowledge of the same objects (e.g., Riddoch \& Humphreys, 1987; Sartori \& Job, 1988; Warrington \& Taylor, 1978). Such patients perform quite poorly when required to name pictured objects, when tested for functional knowledge of what a visual object is used for, or when queried regarding associative knowledge of where an object is typically encountered. But they perform relatively well when given tests that tap knowledge of object structure, such as matching different views of common objects or distinguishing between real and nonsense objects.

There has been a good deal less work on visual object priming than on visual word priming, but as with the visual word form system, three main kinds of evidence implicate the structural description system as a major substrate of priming: spared implicit memory in amnesic patients, invariance of priming across semantic vs. nonsemantic study task manipulations, and effects of study-totest transformation of various stimulus properties. I will first consider each type of evidence in the context of an experimental paradigm that my colleagues and I developed to test the structural description system hypothesis, and then briefly note pertinent data from other, related implicit memory tasks.

The paradigm that we have developed for examining priming of structural descriptions makes use of twodimensional line drawings that depict unfamiliar threedimensional visual objects (see Fig. 1). Although all of the objects are novel, half of them are structurally possible-they could exist in three-dimensional formwhereas the other half are structurally impossible-they contain surface and edge violations that would prohibit them from existing in three-dimensions (see Schacter, Cooper, \& Delaney, 1990, for more details on objects). In a typical experiment, subjects initially study a list of possible and impossible objects by making various kinds of judgments about them, and are then given an object decision test to assess priming, or a yes/no recognition test to assess explicit memory. For the object decision test, previously studied and nonstudied objects are presented quite briefly (e.g., 50-100 msec), one at a time, and subjects decide whether they are possible or impossible. The reasoning is that (1) making the possible/ impossible object decision requires access to information about three-dimensional structure of an object, and (2) to the extent that subjects have acquired information about object structure during the study trial, object de- 


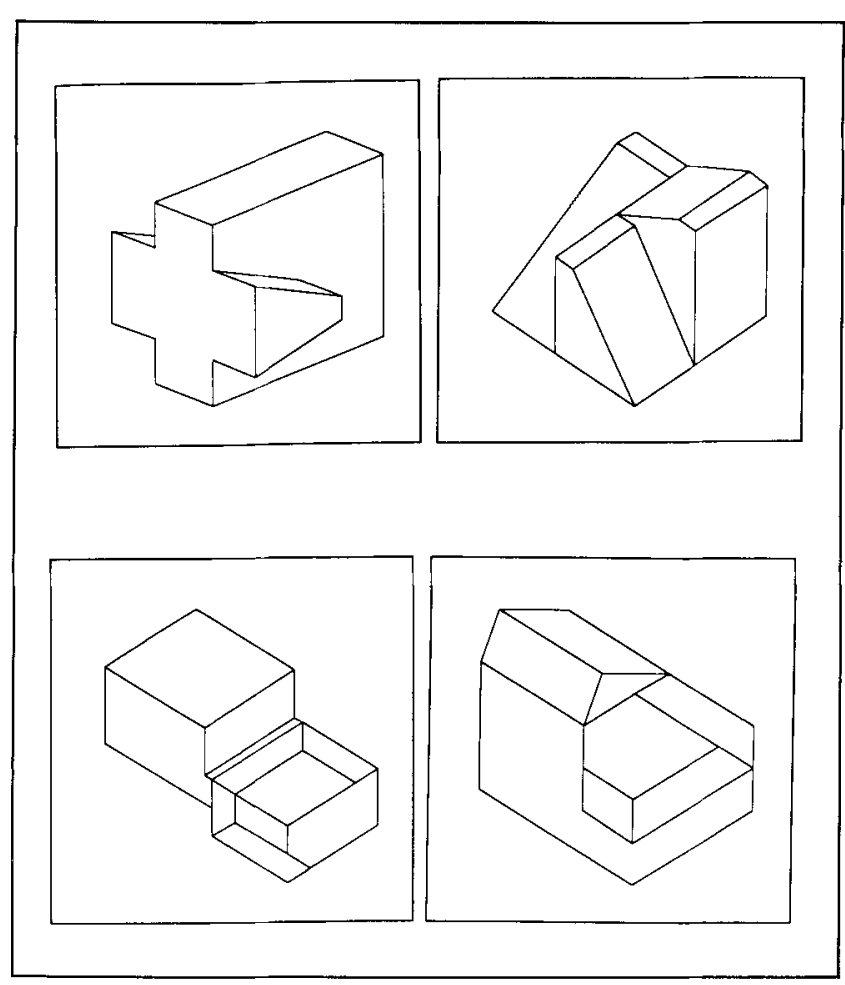

Figure 1. Sample of drawings used in experiments on implicit and explicit memory for novel objects. The drawings in the upper row depict possible objects that could exist in three-dimensional form. The drawings in the lower row depict impossible objects that contain structural violations that would prohibit them from actually existing in three-dimensional form. See text for further explanation.

cisions should be more accurate for previously studied objects than for nonstudied objects. An initial experiment revealed that significant priming is observed on the object decision task following a study task that requires analysis of global object structure but not following a study task that focuses attention on local object features (Schacter, Cooper, \& Delaney, 1990). Moreover, the priming effect was observed for structurally possible objects but not for structurally impossible objects. The failure to observe priming of impossible objects has been replicated many times, and may indicate that it is difficult to form an internal representation of the global structure of an impossible object (see Schacter, Cooper, \& Delaney, 1990; Schacter, Cooper, Delaney, Tharan, \& Peterson, 1991).

The foregoing findings are consistent with the idea that priming on the object decision task is supported by newly formed structural descriptions of previously studied objects. Evidence that the priming effect reflects the operation of a presemantic structural description system-distinct from episodic memory-is provided by experiments in which we have compared encoding tasks that require processing of object structure (e.g., deciding whether an object faces primarily to the left or to the right) with encoding tasks that require processing of semantic and functional properties of objects. Figure 2

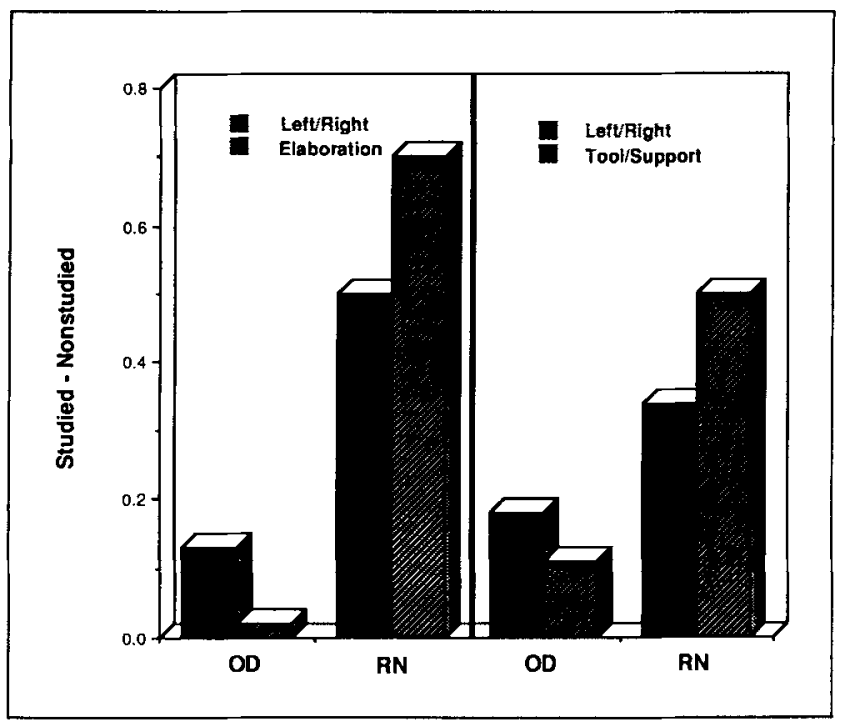

Figure 2. Summary of two experiments examining object decision priming (OD) and recognition memory ( $\mathrm{RN}$ ) using the possible and impossible figures presented in Figure 1. Only data for possible objects are shown, because no priming of impossible objects was observed in either experiment. The left panel presents results from an experiment by Schacter, Cooper, and Delaney (1990) in which subjects initially either judged whether the object faces primarily to the left or to the right, or generated the name of a real-world object that the target reminded them of most. The figure presents priming scores from the object decision task that were computed by subtracting the proportion of nonstudied possible objects classified correctly from the proportion of studied possible objects classified correctly, and corrected recognition scores that were computed by subtracting "yes" responses to nonstudied objects (i.e., false alarms), from "yes" responses to studied objects (hits). The right panel presents priming and corrected recognition scores from an experiment in which subjects performed either the left/right study task or a functional encoding task in which they judged whether an object would be best used as a tool or for support (Schacter \& Cooper, 1991).

displays the results of two such experiments. The leftmost panel depicts priming and recognition scores following a structural encoding task (left/right judgment) and an elaborative encoding task that taps subjects' semantic knowledge of real world objects (they are required to generate a verbal label of a common object that each drawing reminds them of most). A striking crossover interaction was observed (Schacter, Cooper, \& Delaney, 1990): Explicit recognition was much higher following elaborative than structural encoding, whereas the opposite pattern was found for object decision. Indeed, the elaborative task failed to produce significant priming on the object decision task, a finding that is probably attributable to the fact that subjects often based their elaborations on local, two-dimensional features of target objects. The right-most panel shows a similar crossover interaction from an experiment in which the left/right encoding task was compared to a functional encoding task in which subjects decided whether target objects could be best used as a tool or for support (Schacter, Cooper, Delaney, Peterson, \& Tharan, 1991). 
The functional encoding task did, however, produce some priming, probably because making the decision about function requires some analysis of structure.

These results are entirely consistent with the idea that object decision priming depends on a presemantic system that is dedicated to the analysis and representation of object structure, and does not handle information about the semantic and functional properties of objects. We have also found that object decision priming was spared in a group of amnesic patients who showed poor explicit memory for the objects on a recognition test (Schacter, Cooper, Tharan, \& Rubens, 1991). This finding suggests that the priming effect, and the structural description system that supports it, are not critically dependent on the limbic structures that are typically damaged in amnesic patients.

Further information regarding the functional properties and possible neuroanatomical basis of the structural description system is provided by experiments in which we have examined the effects on priming of changing size, reflection, and picture plane orientation of target objects between study and test. The results of these experiments are relatively clear cut: study-to-test changes in size and left/right reflection of objects have no effect on priming despite producing an impairment of recognition memory (Cooper, Schacter, Ballesteros, \& Moore, 1992), whereas changing the picture plane orientation of target objects by 120,180 , or 240 degrees from a standard orientation eliminates priming and also reduces recognition memory substantially (Cooper, Schacter, \& Moore, 1991). This pattern of results suggests that the structural description system computes object representations that do not include information about size or left-right reflection, but do include information that specifies the relation between the parts of an object on the one hand and its principal axis and reference frame on the other (Cooper et al., 1991, 1992).

Data from other studies on priming of nonverbal information provide converging evidence on the foregoing points. Evidence for the presemantic nature of priming has been obtained on implicit tests that involve completing fragments of familiar pictures with the first object that comes to mind (Schacter, Delaney, \& Merikle, 1990) or identifying novel dot patterns (Musen, 1991). Spared priming of novel dot patterns has also been documented in amnesic patients (Gabrieli, Milberg, Keane, \& Corkin, 1990). And invariance of priming across study-to-test changes in size and reflection has been documented in paradigm that involves naming and renaming pictures of familiar objects (Biederman \& Cooper, 1992).

Although relatively little information is available concerning the exact neural locus of the structural description system, the findings on size and reflection invariant priming have led to the proposal that regions of inferior temporal cortex may be involved (Biederman \& Cooper, 1992; Cooper et al., 1992; Schacter, Cooper, Tharan, \& Rubens, 1991). This idea is based to a large extent on findings from single cell recordings and brain lesions in nonhuman primates indicating that inferior temporal regions are involved in the computation of size and reflection invariant object representations (for review, see Plaut \& Farah, 1990). It is possible, of course, that the precise neuroanatomical locus of this system differs in monkey and man, but the human data on this point are not conclusive. Studies using PET imaging should help to clarify the matter, and we are in the process of completing such a study with the possible/impossible object decision task.

\section{Auditory Word Form System}

The great majority of research on priming and implicit memory has focused on visual paradigms and processes; there has been relatively little investigation of, and theorizing about, implicit memory in the auditory domain (see Schacter \& Church, 1992, for review). Nevertheless, neuropsychological evidence on auditory processing deficits has revealed a form/semantic dissociation that is similar in kind to those discussed in previous sections, and that implicates the existence of a presemantic auditory subsystem of PRS. Specifically, patients have been identified who exhibit severe deficits in understanding spoken language together with relatively intact abilities to repeat and write-to-dictation auditorily presented words and sentences. In cases of word meaning deafness, the semantic deficit is modality specific; patients show relatively spared comprehension of visual inputs (e.g., Kohn \& Friedman, 1986). In cases of transcortical sensory aphasia, comprehension is impaired in both the auditory and visual modalities (e.g., Coslett, Roeltgen, Rothi, \& Heilman, 1987). By contrast, patients characterized by pure word deafness exhibit selective deficits in repetition of spoken words (e.g., Metz-Lutz \& Dahl, 1984). Taken together, these observations point toward the existence of a presemantic auditory word form system that is dedicated to the processing and representation of acoustic/phonological information, but not semantic information, about spoken words (Ellis \& Young, 1988). PET studies suggest that regions of posterior temporoparietal cortex may be involved in encoding of phonological word forms (Peterson et al., 1989).

Relatively little work has been done to link the auditory word form system with priming effects that have been observed on auditory implicit tests, but some data are available concerning two of the key issues discussed in previous sections: invariance of priming as a function of semantic vs. nonsemantic encoding processes, and effects of study-to-test changes in perceptual attributes of targets on the magnitude of priming.

Several recent experiments from our laboratory have provided evidence supporting the idea that auditory priming depends on a presemantic system. In studies with college students, we have examined auditory priming on two tests that are quite similar to the perceptual 
or data-driven implicit memory tasks used previously in the visual domain: auditory word identification and auditory stem completion (Schacter \& Church, 1992). In the former task, subjects hear previously studied and nonstudied words that are masked by white noise, and attempt to identify them; in the latter task, subjects hear the initial syllable of studied and nonstudied words, and respond with the first word that pops to mind (the syllable stimulus is created by editing a whole word utterance on a Macintosh system). To investigate whether priming on these tasks depends on semantic-level processes, during the study phase of the experiment subjects heard a series of spoken words and either performed a semantic encoding task (e.g., rating the number of meanings associated with the word) or a nonsemantic encoding task (e.g., rating the clarity with which the speaker enunciated the word). Implicit and explicit memory were tested after brief delays of several minutes. A series of five experiments yielded a consistent pattern of results: explicit memory was considerably higher following semantic than nonsemantic encoding tasks, whereas the magnitude of priming on identification and completion tasks was either less affected or entirely unaffected by the study task manipulation.

Further evidence bearing on the hypothesis that auditory priming reflects the operation of a presemantic system is provided by a recent study in which we assessed priming in a case of word meaning deafness (Schacter, McGlynn, Milberg, \& Church, 1992). The patient, J. P., suffered a large stroke-induced lesion within the distribution of the left middle cerebral artery that affected primarily the anterior portions of Wernicke's area, largely sparing posterior temporoparietal cortex. He has great difficulty understanding spoken words. For example, J. P. exhibits a severe impairment on the auditory comprehension subtests of the Boston Diagnostic Aphasia Examination, whereas he shows only mild deficits on subtests that assess repetition of spoken words, writing to dictation, or comprehension of visual input. If, as we have suggested, priming on a task such as auditory word identification is mediated by a presemantic system, then J. P. should show robust priming despite his semantic impairment. Using the identification-innoise task from Schacter and Church (1992), we indeed observed intact priming in J. P. relative to four matched control subjects (Fig. 3).

While the foregoing results support the idea that auditory priming need not involve access to semantic representations, they do not indicate what kinds of processes and representations are involved in the phenomenon. Evidence that priming is based largely on an auditory perceptual system is provided by experiments on study/ test modality shifts: When target words are studied visually, priming on auditory word identification (Ellis, 1982; Jackson \& Morton, 1984) and stem completion (Bassilli, Smith, \& MacLeod, 1989) tasks is reduced significantly relative to auditory study conditions. Given that

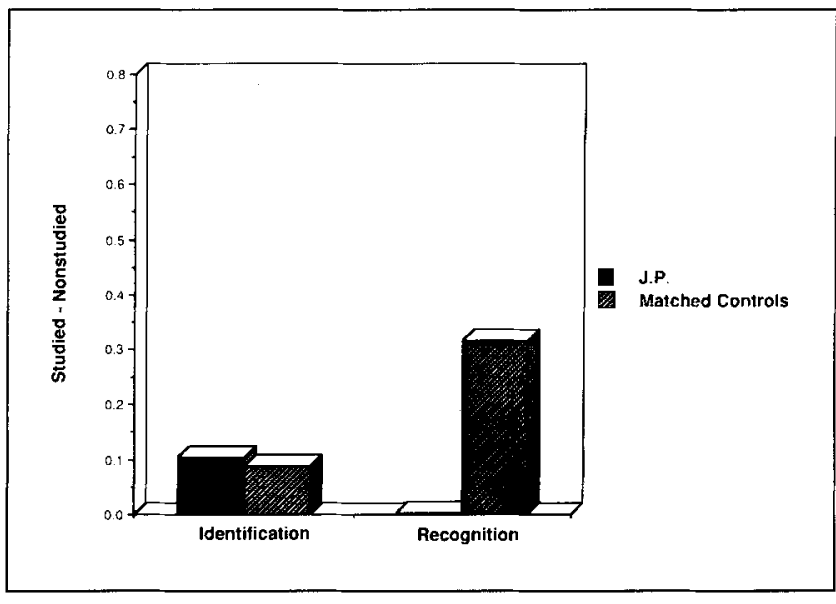

Figure 3. Results of an experiment that examined priming of auditory word identification and explicit recognition memory in a patient with word meaning deafness (J. P.) and four matched controls (Schacter, McGlynn, Milberg, \& Church, 1992). The figure presents priming scores from the auditory identification task that were computed by subtracting the proportion of nonstudied words identified correctly from the proportion of studied words identified correctly, and corrected recognition scores that were computed by subtracting "yes" responses to nonstudied words from "yes" responses to studied words. J. P.'s corrected recognition score was zero.

a modality-specific auditory system plays a key role in priming, an important question concerns the nature of this system: Is auditory priming based on acoustic features of spoken input that are specific to a particular speaker, or is priming based on more abstract phonological representations that do not include speaker-specific perceptual information?

The issue was addressed initially in experiments by Jackson and Morton (1984), who examined priming on the auditory identification test when target words were spoken by the same voice at study and test, and when they were spoken by different voices (male vs. female) at study and test. They observed priming effects of comparable magnitude in the same- and different-voice conditions, and argued on this basis that priming depends entirely on abstract (but modality specific) representations of invariant phonological features of spoken words. In experiments discussed earlier, Schacter and Church (1992) also found nonsignificant effects of study-to-test changes in speaker's voice on priming of auditory identification performance. In fact, Schacter and Church observed voice-invariant priming even following nonsemantic study tasks that focused subjects' attention on characteristics of speaker's voice (cf. Graf \& Ryan, 1990).

While the foregoing results are consistent with the idea that auditory priming depends on a system that represents abstract phonological word forms, it is also possible that the absence of voice-change effects in the Jackson and Morton (1984) and Schacter and Church (1992) experiments reflects idiosyncratic features of the auditory identification test that was used in these experiments. 
Specifically, Schacter and Church suggested that the use of white noise on the identification test may have interfered with processing those components of the acoustic waveform that provide access to voice information. Consistent with this suggestion, when we examined the effect of changing speaker's voice on priming of the auditory stem completion task-which does not involve the use of white noise-significant voice change effects were observed in each of two experiments. Data from one of those experiments are presented in Figure 4, which shows that priming was lower in the different-voice than in the same-voice condition following both semantic and nonsemantic encoding tasks. The voice change manipulation had no effect on explicit memory, whereas the semantic vs. nonsemantic study task manipulation affected explicit memory but not priming. To ascertain that the presence/absence of white noise is the critical factor determining whether voice changes effects on priming are or are not observed, we performed an additional experiment with auditory stem completion that was identical in all respects to the previous one except for one change: stems were masked by white noise. Under these conditions, we observed significant priming but no effect of voice change (Schacter and Church, 1992).

This general pattern of results is similar to that observed in studies of visual word priming: priming is influenced by changes in perceptual features of target words in some experimental conditions but not in others. The critical issue for the present purposes concerns the theoretical implications of such observations for understanding the kind of subsystem that subserves auditory priming. Schacter and Church (1992) offered one speculative possibility that implicates left and right hemi-

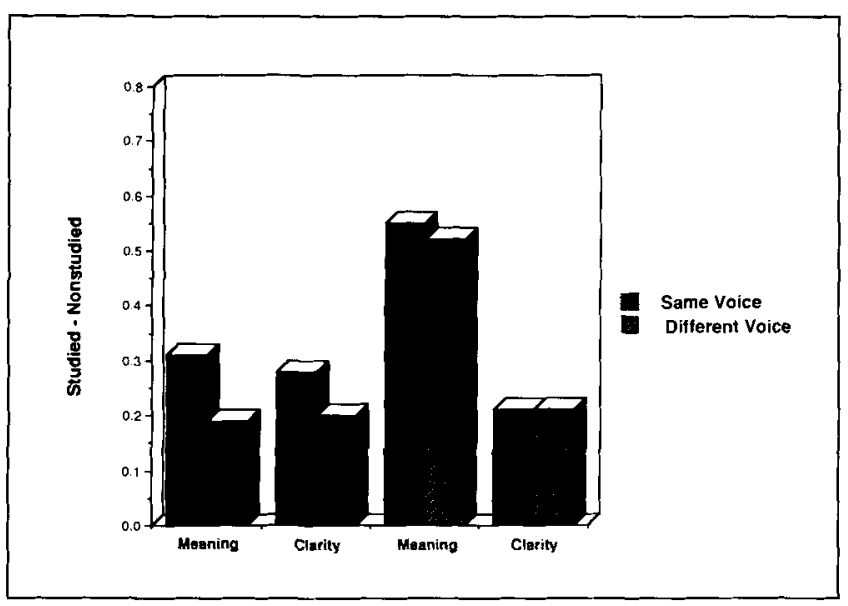

Figure 4. Results of an experiment that examined priming of auditory stem completion and explicit cued recall following word meaning and voice clarity encoding tasks (Schacter \& Church, 1992). Target words were spoken in the same voice or a different voice at study and test. The figure presents priming scores and corrected recall scores that were computed by subtracting the proportion of nonstudied target words that subjects provided from the proportion of studied target words that they provided. sphere subsystems in abstract and perceptually specific components of auditory priming, respectively. The reasoning is relatively straightforward, and turns on three kinds of observations. First, a number of investigators have argued that the left hemisphere represents abstract or categorical phonological information, whereas the right hemisphere represents perceptually specific "acoustic gestalts," including information about speaker's voice (cf. Gazzaniga, 1975; Lieberman, 1982; Mann \& Lieberman, 1983; Sidtis \& Gazzaniga, 1981; Zaidel, 1985). Second, several types of empirical evidence link the right hemisphere with access to voice information: patients with right hemisphere lesions are characterized by voice recognition impairments (e.g., Van Lancker \& Kreiman, 1987 ) and by difficulties in processing voice prosody (e.g., Ross, 1981); and studies of normal subjects using dichotic listening techniques have shown a left-ear (i.e., right hemisphere) advantage for processing intonational contours (e.g., Blumstein \& Cooper, 1974). Third, evidence from split-brain patients indicates that the right hemisphere is greatly impaired-more than the leftwhen required to process spoken words that are presented in background noise (Zaidel, 1978).

Given that voice-change effects in auditory priming appear to be dependent on white noise, and that the right hemisphere represents voice information and is especially sensitive to background noise, it is possible that voice change effects are not observed when target items are masked by noise because a right hemisphere subsystem has been effectively excluded from contributing to task performance. Stated slightly differently, auditory priming may depend both on a left hemisphere subsystem that represents abstract phonological information and a right hemisphere subsystem that represents voice-specific acoustic information. When both subsystems can contribute to implicit task performance (i.e., if no white noise is used), voice change effects will be observed; but when only the left hemisphere subsystem can contribute (i.e., if white noise eliminates right hemisphere contributions), voice change effects will not be observed. The general idea that two lateralized subsystems are involved in auditory priming is quite similar to that offered by Marsolek et al. (1992) to account for the finding that perceptual specificity effects in visual word priming were observed when test stems were presented to the right hemisphere, whereas abstract priming was observed when stems were presented to the left hemisphere.

It must be emphasized, of course, that Schacter and Church's argument for right hemisphere involvement in voice specific priming is based entirely on indirect evidence and hence must be treated cautiously. To test this hypothesis more directly, we have recently initiated experiments that use dichotic listening techniques to examine voice change effects on priming. A large body of literature indicates that with dichotic presentation, verbal stimuli presented to the right ear (i.e., left hemisphere) 
are more accurately reported than are verbal stimuli presented to the left ear (e.g., Bryden, 1988; Wexler, 1988) and, as noted earlier, there is some evidence that voice information is processed more efficiently by the left ear (i.e., right hemisphere; Blumstein \& Cooper, 1974). Accordingly, we hypothesized that priming effects would be reduced by study-to-test changes in speaker's voice when test stimuli were presented to the left ear, but not when they were presented to the right ear. In the one experiment that we have completed (Schacter, Aminoff, \& Church, 1992), subjects initially made clarityof-enunciation judgments concerning a series of words that were spoken by male or female voices. They were then given a dichotic version of the auditory stem completion task: Stems representing studied or nonstudied target words were presented to either the left or right ear, a nontarget distractor stem was presented to the opposite ear (to inhibit the hemisphere ipsilateral to the target stimulus), and subjects were instructed to respond with the first word that came to mind in response to the stem presented to either the left ear or the right ear (left ear and right ear presentations were ordered randomly for individual subjects, and they were cued to the appropriate ear on each test trial). Results indicated that for right-ear presentations, virtually identical amounts of priming were observed in same- and different-voice conditions, whereas for left-ear presentations, more priming was observed in the same-voice than in the differentvoice condition. Indeed, left-ear presentations did not yield a significant priming effect in the different-voice condition. In view of the fact that data from dichotic listening experiments are sometimes variable across procedures and subject populations (e.g., Harshman, 1988), these data must be treated cautiously pending replication. Nevertheless, they support the idea that two lateralized subsystems are involved in voice-specific and voice-nonspecific components of auditory priming.

Taken together, experiments examining semantic vs. nonsemantic study processing and study-to-test changes in speaker's voice support the idea that presemantic PRS subsystems support auditory priming. Note, however, that no published studies of amnesic patients are available that bear directly on these hypotheses. In a recently completed experiment, we examined auditory priming in a mixed group of Korsakoff and non-Korsakoff amnesic patients (Schacter, Church, \& Treadwell, 1992). Using the auditory identification test and the semantic/ nonsemantic study tasks developed by Schacter and Church (1992, Experiment 2), we observed entirely normal priming in the amnesic group. These results provide converging evidence for the PRS account.

\section{CONCLUDING COMMENTS: SYSTEMS AND SUBSYSTEMS}

This article has focused on the contributions of presemantic perceptual subsystems to priming effects on data-driven implicit memory tests in visual and auditory domains. However, it can be questioned whether the entire priming effect on such tasks can be attributed to perceptual processes. As noted earlier, experiments examining the effects of study-to-test modality shifts have reported reduced priming in cross-modality conditions relative to within-modality conditions, but have generally documented significant cross-modal effects; priming is rarely eliminated by modality shifts (for review, see Kirsner et al., 1989; Roediger \& Blaxton, 1987). Some authors have assumed that the existence of cross-modal priming necessarily implies the involvement of semantic or conceptual processes in priming (e.g., Hirshman, Snodgrass, Mindes, \& Feenan, 1990; Keane, Gabrieli, Fennema, Growdon, \& Corkin, 1991). For example, Keane et al. (1991) have argued that the existence of significant cross-modal priming on the stem completion task indicates that a lexical/semantic system plays a role in stem completion priming. If their reasoning is correct, it will be necessary to qualify the statement that priming on stem completion (and other tasks that include a significant cross-modal component) is mediated entirely by subsystems that operate at a presemantic level (see also Masson and Macleod, 1992).

There are, however, some grounds for questioning the conclusion that cross-modal priming necessarily implicates the involvement of semantic-level processes. Kirsner et al. (1989), for instance, have suggested two alternative sources of cross-modal priming on visual implicit tests: phonological representations or amodal "production records" (i.e., motor programs involved in response production) that are activated by an auditory study presentation. Their own review of the literature led Kirsner et al. to favor the production record hypothesis. Similarly, McClelland and Pring (1991) provided evidence supporting the hypothesis that cross-modal effects on priming of auditory stem completion are attributable to phonological processes. Whether or not these ideas about the basis of cross-modal priming are ultimately correct, they underscore the point that the presence of cross-modal priming need not signal the involvement of conceptual or semantic processes. Nevertheless, it is clear that priming can be observed on tasks that involve semantic processing, such as answering general knowledge questions or producing category instances in response to a category label. The magnitude of priming on such tasks is increased by semantic relative to nonsemantic study processing (Hamann, 1990) and can be dissociated from perceptually based priming (Blaxton, 1989). These kinds of observations indicate that conceptual priming is based on different processes than perceptual priming (Blaxton, 1989; Roediger, 1990; Tulving \& Schacter, 1990)-processes that occur outside of PRS - although the precise locus of the effects has not been well specified.

This article has focused on three PRS subsystems: visual word form, structural description, and auditory word 
form. In each case, the existence of a putative subsystem was postulated on the basis of neuropsychological observations concerning patients who exhibit form/semantic dissociations within a particular domain; the role of that subsystem in priming was inferred from patterns of effects of various experimental and subject variables. The fact that the PRS account is supported by converging evidence from independent research domains is an important strength of this general approach (see Schacter, 1992). However, results were also considered that support a further fractionation of the visual and auditory word form systems into lateralized subsystems: a lefthemisphere component that operates on abstract (but modality-specific) word form information, and a righthemisphere component that operates on highly specific visual or auditory perceptual information. Experimental evidence supporting the idea that such lateralized subsystems contribute differentially to priming in visual and auditory domains is still rather scanty, and will require further replication and examination. Nonetheless, it is worth emphasizing that there is converging evidence for lateralized subsystems of the kind that have been postulated on the basis of the priming results: in the visual domain, recent PET data are consistent with the idea that left posterior regions are involved in processing abstract orthographic information whereas right posterior regions are involved in processing specific perceptual features of words and nonwords (Petersen, Fox, Snyder, \& Raichle, 1990); and in the auditory domain, several kinds of evidence discussed earlier (see also Schacter \& Church, 1992) suggest the existence of abstract and specific auditory subsystems.

If we accept for the moment the idea that lateralized perceptual subsystems contribute to priming, questions arise concerning the nature of their relation to the three subsystems that have been the focus of this article: Is it necessary to fractionate the visual word form, structural description, and auditory word form systems into lefthemisphere and right-hemisphere subsystems, yielding a total of six distinct PRS subsystems? Or is it more useful to think in terms of a visual form system and an auditory form system that can each be fractionated into left- and right-hemisphere components, yielding four basic PRS subsystems? Although we cannot provide conclusive answers to these questions at this early stage of research and theorizing, they raise fundamental problems that will require careful analysis. It is likely that progress in thinking about such questions with respect to implicit memory will be facilitated by considering them in relation to debates in cognitive neuropsychology concerning the nature and number of visual and auditory recognition systems (e.g., Farah, 1991; Humphreys \& Riddoch, 1987; Ellis \& Young, 1988).

Questions concerning relations among PRS subsystems raise a more general issue concerning the use of the terms "system" and "subsystem" in discussion of PRS and multiple memory systems more generally. Throughout this article and elsewhere, I have referred to a perceptual representation system and to visual word form, structural description, and auditory word form subsystems. The latter term is used to reflect the idea that each of the subsystems performs distinct input-output computations within a particular domain. For example, the kinds of modality-specific computations performed by the visual and auditory word form subsystems, and the memory representations that they create, must differ from one another because of fundamental differences in the nature of visual and acoustic inputs to these subsystems. Similarly, as noted earlier, the computational case for postulating lateralized subsystems rests on the notion that the computations performed by abstract (left hemisphere) and specific (right hemisphere) perceptual subsystems are functionally incompatible with one another (Marsolek et al., 1992; Sherry \& Schacter, 1987). In view of these considerations, one could argue that it is more accurate to refer simply to perceptual representation systems than to invoke a monolithic perceptual representation system. I have indeed used the terms "perceptual representation systems" and "perceptual representation system" interchangeably (Schacter, 1990), and the spirit of theorizing presented in this article and elsewhere is entirely consistent with such usage. The main reason for invoking the term perceptual representation system is to emphasize the notion that all of the various subsystems are tied together by common features: they are cortically based, operate at a presemantic level on domain-specific perceptual information, and support nonconscious expressions of memory. Thus, the term subsystem is used to refer to a neurally instantiated input-ouput unit that performs certain kinds of memory functions, whereas the term system is used at a more abstract level of description to refer to common features of a class of subsystems. Further consideration of the ways in which these and other terms are used will be necessary not only with respect to the particular issues addressed in this article, but also in more general discussions and debates concerning the nature and number of memory systems.

\section{Acknowlegments}

Supported by Air Force Office of Scientific Research Grant 910182 and National Institute on Aging Grant RO1 AG08441.

\section{REFERENCES}

Bassilli, J. N., Smith, M. C., \& Macleod, C. M. (1989). Auditory and visual word stem completion: Separating data-driven and conceptually-driven processes. Quarterly Journal of Experimental Psychology, 41A, 439-453.

Biederman, I., \& Cooper, E. E. (1992). Evidence for complete translational and reflectional invariance in visual object priming. Perception, in press.

Blaxton, T. A. (1989). Investigating dissociations among memory measures: Support for a transfer appropriate processing framework. Joumal of Experimental Psuchologv: Learning. Memory and Cognition, 15. 657-668. 
Blumstein, S., \& Cooper, W. E. (1974). Hemispheric processing of intonation contours. Cortex, 10, 146-158.

Bowers, J. S., \& Schacter, D. L. (1990). Implicit memory and test awareness. Joumal of Experimental Psychology: Leaming. Memory and Cognition 16.404-416.

Bowers, J. S., \& Schacter, D. L. (1992). Priming of novel information in amnesia: Issues and data. In P. Graf \& M. E. J. Masson (Eds.), Implicit memory: New directions in cognition, neuropsychology, and development. New York: Academic Press.

Bryden, M. P. (1988). An overview of the dichotic listening procedure and its relation to cerebral organization. In K. Hugdahl (Ed.), Handbook of dichotic listening: Theory, methods, and research (pp. 1-43). London: John Wiley.

Butters, N., Heindel, W. C., \& Salmon, D. P. (1990). Dissociation of implicit memory in dementia: neurological implications. Bulletin of the Psychonomic Society, 28.

Carr, T. H., Brown, J. S., \& Charalambous, A. (1989). Repetition and reading: Perceptual encoding mechanisms are very abstract but not very interactive. Joumal of Experimental Psychology: Learning, Memorv and Cognition, 15. 763-778.

Cermak, L. S., Chandler, K., \& Wolbarst, L. R. (1985). The perceptual priming phenomenon in amnesia. Neuropsuchologia, 23, 615-622.

Cermak, L. S., Verfaellie, M., Milberg, W., Letourneau, L., \& Blackford, S. (1991). A further analysis of perceptual identification priming in alcoholic Korsakoff patients. Neuronsv. chologia. 22 , 725-736.

Clarke, R., \& Morton, J. (1983). Cross modality facilitation in tachistoscopic word recognition. Quarterly Joumal of Experimental Psycbology, 35A, 79-96.

Cohen, N. J. (1984). Preserved learning in amnesia: Evidence for multiple memory systems. In L. R. Squire \& N. Butters (Eds.), Neuropsychology of memory (pp. 83-103). New York: Guilford Press.

Cohen, N. J., \& Squire, L. R. (1980). Preserved learning and retention of pattern analyzing skill in amnesics: Dissociation of knowing how and knowing that. Science.210, 207210.

Cooper, L. A., Schacter, D. L., Ballesteros, S., \& Moore, C. (1992). Priming and recognition of transformed threedimensional objects: effects of size and reflection. Journal of Experimental Psychology: Learning, Memory and Cognition, 18, 43-57.

Cooper, L. A., Schacter, D. L., \& Moore, C. (1991). Orientation affects both structural and episodic representations of 3-D objects. Paper presented to the Annual Meeting of the Psychonomic Society, San Francisco.

Coslett, H. B., Roeltgen, D. P., Rothi, L. G., \& Heilman, K. M (1987). Transcortical sensory aphasia: Evidence for subtypes. Brain and Lanquage, 32, 362-378.

Craik, F. I. M., \& Tulving, E. (1975). Depth of processing and the retention of words in episodic memory. Journal of $E x$ perimental Psychology: General, 104, 268-294.

Daum, I., Channon, S., \& Canavar, A. (1989). Classical conditioning in patients with severe memory problems. Loumal of Neurology and Neurosurgerv Psichiatry. 52 , 47-51.

Diamond, R. \& Rozin, P. (1984). Activation of existing memo ries in anterograde amnesia. Journal of Abnormal Psychology, 93, 98-105.

Ellis, A. (1982). Modality-specific repetition priming of auditory word recognition. Current Psuchological Research.2, $123-128$.

Ellis, A. W., \& Young, A. W. (1988). Human cognitive neuropsychology. London: Erlbaum.

Farah, M. J. (1991). Patterns of co-occurrence among the associative agnosias: Implications for visual object representation. Cognitive Neuropsychology, 8, 1-19.
Feustel, T. C., Shiffrin, R. M., \& Salasoo, A. (1983). Episodic and lexical contributions to the repetition effect in word identification. Ioumal of Experimental Psychology: General, 112, 309-346.

Gabrieli, J. D. E., \& Keane, M. M. (1988). Priming in the patient H. M.: New findings and a theory of intact and impaired priming in patients with memory disorders. Society for Neuroscience Abstracts, 14, 1290.

Gabrieli, J. D. E., Milberg, W., Keane, M. M., \& Corking, S. (1990). Intact priming of patterns despite impaired memory. Neuropsuchologia, 28, 417-428.

Gardiner, J. M. (1988). Generation and priming effects in word-fragment completion. Journal of Experimental Psychology: Learning Memorv and Cognition, 14, 495-501.

Gazzaniga, M. S. (1975). Partial commissurotomy and cerebral localization of function. In K. J. Zulch, O. Creutzfeldt, G. C. Galbraith (Eds.), Cerebral localization (pp. 133-139). New York: Springer-Verlag.

Glisky, E. L., \& Schacter, D. L. (1987). Acquisition of domainspecific knowledge in organic amnesia: Training for computer-related work. Neuropswcbologia, 25, 893-906.

Glisky, E. L., \& Schacter, D. L. (1988). Long-term retention of computer learning by patients with memory disorders. Neuropsychologia, 26, 173-178.

Glisky, E. L., \& Schacter, D. L. (1989). Extending the limits of complex learning in organic amnesia: Computer training in a vocational domain. Neuropsucbologia, 27, 107-120.

Glisky, E. L., Schacter, D. L., \& Tulving, E. (1986). Computer learning by memory-impaired patients: Acquisition and retention of complex knowledge. Neurobsvchologia, 24, 313328.

Gordon, B. (1988). Preserved learning of novel information in amnesia: Evidence for multiple memory systems. Cognition, 7, 257-282.

Graf, P., \& Mandler, G. (1984). Activation makes words more accessible, but not necessarily more retrievable. Journal of Verbal Learning and Verbal Bebavior, 23, 553-568.

Graf, P., \& Ryan, L. (1990). Transfer-appropriate processing for implicit and explicit memory. Ioumal of Experimental Psvchologv: Learning. Memory and Cognition, 16, 978-992.

Graf, P., \& Schacter, D. L. (1985). Implicit and explicit memory for new associations in normal and amnesic patients. Ioumal of Experimental Psucbology: Learning. Memory and Cognition. $11.501-518$.

Graf, P., Shimamura, A. P., \& Squire, L. R. (1985). Priming across modalities and priming across category levels: Extending the domain of preserved functioning in amnesia. Joumal of Experimental Psychology: Learning, Memory and Cognition, 11, 385-395.

Graf, P., Squire, L. R., \& Mandler, G. (1984). The information that amnesic patients do not forget. Joumal of Experimental Psychology: Learning, Memorv and Cognition, 10,164178

Haist, F., Musen, G., \& Squire, L. R. (1991). Intact priming of words and nonwords in amnesia. Psychobiology, 19, 275285.

Hamann, S. B. (1990). Level of processing effects in conceptually driven implicit tasks. Iournal of Exberimental PSychologv: Learning Memory and Cognition. 16.970-977.

Harshman, R. A. (1988). Dichotic listening assessment of group and individual differences: methodological and practical issues. In K. Hugdahl (Ed.), Handbook of dichotic listening: Theory, methods, and research (pp. 595-646). London: John Wiley.

Hayman, C. A. G., \& Tulving, E. (1989). Contingent dissociation between recognition and fragment completion: The method of triangulation. Journal of Experimental Psychology: Learning, Memory and Cognition. 15.228-240.

Hirshman, E., Snodgrass, J. G., Mindes, J., \& Feenan, K. 
(1990). Conceptual priming in fragment completion. Journal of Experimental Psychology: Learning, Memory and Cognition, 16, 634-647.

Humphreys, G. W., \& Riddoch, M. J. (1987). Visual object processing: A cognitive neuropsychological approach. London: Eribaum.

Jackson, A., \& Morton, J. (1984). Facilitation of auditory word recognition. Memory and Cognition, 12, 568-574.

Jacoby, L. L., \& Dallas, M. (1981). On the relationship between autobiographical memory and perceptual learning. Journal of Experimental Psychology: General. 110, 306-340.

Jacoby, L. L., \& Hayman, C. A. G. (1987). Specific visual transfer in word identification. Ioumal of Experimental Psvchologv: Learning Memorv and Cognition. 13, 456-463.

Jacoby, L. L., Levy, B. A., \& Steinbach, K. (1992). Episodic transfer and automaticity: Integration of data-driven and conceptually-driven processing in rereading. Journal of Experimental Psychology. Learning Memorv and Cognition. $18,15-24$.

Jacoby, L. L., \& Witherspoon, D. (1982). Remembering without awareness. Canadian Journal of Psycbology, 36, 300-324.

Johnson, M. K., \& Hasher, L. (1987). Human learning and memory. Annual Review of Psvchologv. 38, 631-668.

Keane, M. M., Gabrieli, J. D. E., Fennema, A. C., Growdon, J. H., \& Corkin, S. (1991). Evidence for a dissociation between perceptual and conceptual priming in Alzheimer's disease. Behavioral Neuroscience 105, 326-342.

Kirsner, K., Dunn, J. C., \& Standen, P. (1989). Domain-specific resources in word recognition. In S. Lewandowsky, J. C. Dunn, \& K. Kirsner (Eds.), Implicit memory: Theoretical issues (pp. 99-122). Hillsdale, NJ: Erlbaum.

Kirsner, K., \& Smith, M. C. (1974). Modality effects in word identification. Memory \& Cognition, 2, 637-640.

Kirsner, K., Smith, M. C., Lockhart, R. S., King, M. L., \& Jain, M. (1984). The bilingual lexicon: Language specific units in an integrated network. Joumal of Verbal Leaming and Verbal Behavior. 23, 519-539.

Kohn, S. E., \& Friedman, R. B. (1986). Word-meaning deafness: A phonological-semantic dissociation. Cognitive Neuropsychology, 3, 291-308.

Kosslyn, S. M., Flynn, R. A., Amsterdam, J. B., \& Wang, G. (1990). Components of high-level vision: A cognitive neuroscience analysis and accounts of neurological syndromes. Cognition. 34, 203-277.

Lieberman, A. M. (1982). On finding that speech is special. American Psuchologist. 37, 148-167.

Mann, V. A., \& Lieberman, A. M. (1983), Some differences between phonetic and auditory modes of perception. Cognition 14, 211-235.

Marsolek, C. J., Kosslyn, S. M., \& Squire, L. R. (1992). Form specific visual priming in the right cerebral hemisphere. Iournal of Experimental Psvchologv: Learning. Memory and Cognition. 18.492-508.

Masson, M. E. J., \& MacLeod, C. M. (1992). Re-enacting the route to interpretation: Context dependency in encoding and retrieval. Joumal of Experimental Psycbology: General.

McClelland, A. G. R., \& Pring, L. (1991). An investigation of cross-modality effects in implicit and explicit memory. Quarterly Journal of Experimental Psycbology, 43A, 19-33.

Metz-Lutz, M. N., \& Dahl, E. (1984). Analysis of word comprehension in a case of pure word deafness. Brain and Language 13-25.

Milner, B., Corkin, S., \& Teuber, H. L. (1968). Further analysis of the hippocampal amnesic syndrome: Fourteen year follow-up study of H. M. Neurobsuchologia. 6, 215-234.

Morton, J. (1979). Facilitation in word recognition: Experiments causing change in the logogen model. In P. A. Kolers, M. E. Wrolstad, \& H. Bouma (Eds.), Processing models of visible language (pp. 259-268). New York: Plenum.

Moscovitch, M. (1982). Multiple dissociations of function in amnesia. In L. S. Cermak (Ed.), Human memory and am nesia (pp. 337-370). Hillsdale, NJ: Erlbaum.

Musen, G. (1991). Effects of verbal labeling and exposure duration on implicit memory for visual patterns. Journal of Experimental Psvchology: Learning. Memory and Cognition, 17, 954-962.

Musen, G., \& Squire, L. R. (1991). Normal acquisition of novel verbal information in amnesia. Journal of Experimental Psychology: Learning, Memory and Cognition, 17, 10951104.

Musen, G., \& Triesman, A. (1990). Implicit and explicit memory for visual patterns. Joumal of Experimental Psychology: Learning, Memory and Cognition, 16, 127-137.

Peterson, S. E., Fox, P. T., Posner, M. I., Mintun, M. A., \& Raichle, M. E. (1989). Positron emission tomographic studies of the processing of single words. Iournal of Cognitive Neuroscience, 1, 153-170.

Petersen, S. E., Fox, P. T., Synder, A. Z., \& Raichle, M. E. (1990). Activation of extrastriate and frontal cortical areas by visual words and word-like stimuli. Science, 249, 10411044.

Plaut, D. C., \& Farah, M. J. (1990). Visual object representation: Interpreting neurophysiological data within a computational framework. Iournal of Cognitive Neuroscience, 2 , 320-343.

Polster, M. R., Nadel, L., \& Schacter, D. L. (1991). Cognitive neuroscience analyses of memory. A historical perspective. Journal of Cognitive Neuroscience. 3, 95-116.

Richardson-Klavehn, A., \& Bjork, R. A. (1988). Measures of memory. Annual Review of Psychologv, 36, 475-543.

Riddoch, M. J., \& Humphreys, G. W. (1987). Visual object processing in optic aphasia: A case of semantic access agnosia. Cognitive Neuropsuchology. 4, 131-186.

Roediger, H. L. (1990). Implicit memory: Retention without remembering. American Psychologist. 45, 1043-1056.

Roediger, H. L., \& Blaxton, T. A. (1987). Effects of varying modality, surface features, and retention interval on priming in word fragment completion. Memory and Cognition, 15, 379-388.

Roediger, H. L., Weldon, M. S., \& Challis, B. H. (1989). Explaining dissociations between implicit and explicit measures of retention: A processing account. In H. L. Roediger \& F. I. M. Craik (Eds.), Varieties of memory and consciousness: Essays in bonor of Endel Tulving (pp. 3-41). Hillsdale, NJ: Erlbaum.

Roediger, H. L., Weldon, M. S., Stadler, M. L., \& Riegler, G. L. (1992). Direct comparison of two implicit memory tests: word fragment and word stem completion. Joumal of Experimental Psychology: Learning, Memory and Cognition, in press.

Ross, E. D. (1981). The aprosodias: Functional-anatomic organization of the affective components of language in the right hemisphere. Archives of Neurology, 38, 561-569.

Rozin, P. (1976). The psychobiological approach to human memory. In M. R. Rosenzweig \& E. L. Bennet (Eds.), Neural mechanisms of learning and memory. Cambridge, MA: MIT Press.

Rueckle, J. G. (1990). Similarity effects in word and pseudoword repetition priming. Ioumal of Experimental Psuchologv Leaming Memory and Cognition. 16.374-391.

Sartori, G., \& Job, R. (1988). The oyster with four legs: A neuropsychological study on the interaction of visual and semantic information. Cognitive Neurobsuchology 5 , 105132.

Sartori, G., Masterson, J., \& Job, R. (1987). Direct-route reading and the locus of lexical decision. In M. Coltheart, 
G. Sartori, \& R. Job (Eds.), The cognitive neuropsychology of language (pp. 59-78). London: Erlbaum.

Scarborough, D. L., Cortese, C., \& Scarborough, H. S. (1977). Frequency and repetition effects in lexical memory. Iournal of Experimental Psuchology: Human Perception and Performance, 3, 1-17.

Schacter, D. L. (1985). Priming of old and new knowledge in amnesic patients and normal subjects. Annals of the New York Academv of Sciences, 444, 44-53.

Schacter, D. L. (1987). Implicit memory: History and current status. Joumal of Experimental Psychology: Learning, Memorv and Cognition, 13, 501-518.

Schacter, D. L. (1990). Perceptual representation systems and implicit memory: Toward a resolution of the multiple memory systems debate. Annals of the New York Academy of Sciences, 608, 543-571.

Schacter, D. L. (1992). Understanding implicit memory: A cog nitive neuroscience approach. American Psvchologist. 47, 559-569.

Schacter, D. L., Aminoff, A., \& Church, B. A. (1992). [A dichotic listening study of voice-specific priming in auditory stem completion.] Unpublished data.

Schacter, D. L., Chiu, C. Y. P., \& Ochsner, K. N. (1993). Implicit memory: A selective review. Annual Review of Neuroscience.

Schacter, D. L., \& Church, B. (1992). Auditory priming: Implicit and explicit memory for words and voices. Journal of Experimental Psycbology: Learning, Memory and Cognition.

Schacter, D. L, Church, B. A., \& Treadwell, J. (1992). [Priming of auditory word identification in amnesic patients.] Unpublished data.

Schacter, D. L., Cooper, L. A., \& Delaney, S. M. (1990). Implicit memory for unfamiliar objects depends on access to structural descriptions. Joumal of Experimental Psychology: General. 119. 5-24.

Schacter, D. L., Cooper, L. A., Delaney, S. M., Peterson, M. A., \& Tharan, M. (1991). Implicit memory for possible and impossible objects: Constraints on the construction of structural descriptions. Ioumal of Experimental Psychology: Learning. Memorv and Cognition, 17, 3-19.

Schacter, D. L., Cooper, L. A., Tharan, M., \& Rubens, A. B. (1991). Preserved priming of novel objects in patients with memory disorders. Journal of Cognitive Neuroscience, 3 , 118-131.

Schacter, D. L., Delaney, S. M., \& Merikle, E. P. (1990). Priming of nonverbal information and the nature of implicit memory. In G. H. Bower (Ed.), The psychology of learning and motivation (pp. 83-123) New York: Academic Press.

Schacter, D. L., McGlynn, S. M., Milberg, W., \& Church, B. A. (1992). Manuscript in Preparation.

Schwartz, M. F., Saffran, E. M., \& Marin, O. S. M. (1980). Fractionating the reading process in dementia: Evidence for word specific print-to-sound associations. In M. Coltheart, K. Patterson, \& J. C. Marshall (Eds.), Deep dyslexia (pp. 259-269). London: Routledge and Kegan Paul.

Scoville, W. B., \& Milner, B. (1957). Loss of recent memory after bilateral hippocampal lesions. Joumal of Neurology and Neurosurgery and Psychiatry, 20, 11-21.

Sherry, D. F., \& Schacter, D. L. (1987). The evolution of multiple memory systems. Psuchological Review. 94, 439-454.

Shimamura, A. P. (1986). Priming effects in amnesia: Evidence for a dissociable memory function. Quarterly Journal of Experimental Psychology, 38A, 619-644.

Shimamura, A. P., \& Squire, L. R. (1984). Paired-associate learning and priming effects in amnesia: A neuropsycholog ical approach. Iournal of Experimental Psvchology: General, 113, 556-570.

Sidtis, J. J., \& Gazzaniga, M. S. (1981). Complex pitch percep- tion after callosal section: further evidence for a right hemisphere mechanism. Iournal of the Acoustical Societv of America, 69, S119.

Smith, M. E., \& Oscar-Berman, M. (1990). Repetition priming of words and pseudowords in divided attention and amne sia. Joumal of Experimental Psychology: Learning, Memory and Cognition, 16, 1033-1042.

Squire, L. R. (1987). Memory and brain. New York: Oxford University Press.

Squire, L. R. (1992). Memory and the hippocampus: A synthesis from findings with rats, monkeys, and humans. Psychological Review, 99, 195-231.

Sutherland, N. S. (1968). Outline of a theory of pattern recognition in animal and man. Proceedings of the Roval Societv of London. B 171, 297-317.

Tardif, T., \& Craik, F. I. M. (1989). Reading a week later: Perceptual and conceptual factors. Journal of Memory and Language, 28, 107-125.

Tulving, E. (1985). How many memory systems are there? American Psychologist. 40, 385-598.

Tulving, E., Hayman, C. A. G., \& MacDonald, C. (1991). Longlasting perceptual priming and semantic learning in amnesia: A case experiment. Journal of Experimental Psychology: Learning, Memory and Cognition, 17, 595-617.

Tulving, E., \& Schacter, D. L. (1990). Priming and human memory systems, Science. 247, 301-306.

Van Lancker, D., \& Kreiman, J. (1987). Voice discrimination and recognition are separate abilities. Neuropsychologia. 25, 829-834.

Warrington, E. K. (1975). The selective impairment of semantic memory. Ouarterlv Journal of Experimental Psvchologv. $27,635-657$.

Warrington, E. K. (1982). Neuropsychological studies of object recognition. Philosophical Transactions of the Roval Societv of London Series $B, 289,15-33$.

Warrington, E. K., \& Shallice, T. (1980), Word-form dyslexia. Brain, 30, 99-112.

Warrington, E, K., \& Taylor, A. M. (1978). Two categorical stages of object recognition. Perception 7, 695-705.

Warrington, E. K, \& Weiskrantz, L. (1974). The effect of prior learning on subsequent retention in amnesic patients. Neuropsychologia, 12, 419-428.

Weiskrantz, L. (1985). On issues and theories of the human amnesic syndrome. In N. M. Weinberger, J. L. McGaugh, \& G. Lynch (Eds.), Memory systems of the buman brain: Animal and buman cognitive processes (pp. 380-415). New York: Guilford Press.

Weiskrantz, L., \& Warrington, E. K. (1979). Conditioning in amnesic patients. Neuropsvchologia. 17, 187-194.

Wexler, B. E. (1988), Dichotic presentation as a method for single hemisphere stimulation studies. In K. Hugdahl (Ed.), Handbook of dicbotic listening: Theory, methods and research (pp. 85-115). London: John Wiley.

Whittlesea, B. W. A. (1990). Perceptual encoding mechanisms are tricky but may be very interactive: Comment on Carr, Brown, and Charalambous (1989). Iournal of Experimental Psychology: Learning, Memory and Cognition, 16, 727-730.

Winston, P. H. (1975). Learning structural descriptions from examples. In P. H. Winston (Ed.), The psychology of computer vision (pp. 157-209). New York: McGraw-Hill.

Zaidel, E. (1978). Concepts of cerebral dominance in the split brain. In P. A. Buser \& A. Rougel-Buser (Eds.), Cerebral correlates of conscious experience (pp. 263-284). Amster dam: Elsevier.

Zaidel, E. (1985). Language in the right hemisphere, In D. F, Benson \& E. Zaidel (Eds.), The dual brain: Hemispheric specialization in bumans (pp, 205-231). New York: Guilford Press. 


\section{This article has been cited by:}

1. Maryse Delaunay-El Allam, Robert Soussignan, Bruno Patris, Luc Marlier, Benoist Schaal. 2010. Long-lasting memory for an odor acquired at the mother's breast. Developmental Science . [CrossRef]

2. Becky Sweeney DeFrancisco Carolyn Rovee-Collier. 2008. The specificity of priming effects over the first year of life. Developmental Psychobiology 50:5, 486-501. [CrossRef]

3. N. E. A. Kroll, A. P. Yonelinas, M. M. Kishiyama, K. Baynes, R. T. Knight, M. S. Gazzaniga. 2003. The Neural Substrates of Visual Implicit Memory: Do the Two Hemispheres Play Different Roles?The Neural Substrates of Visual Implicit Memory: Do the Two Hemispheres Play Different Roles?. Journal of Cognitive Neuroscience 15:6, 833-842. [Abstract] [PDF] [PDF Plus]

4. Maya Misra, Phillip J Holcomb. 2003. Event-related potential indices of masked repetition priming. Psychophysiology 40:1, 115-130. [CrossRef]

5. Karine Lebreton, Béatrice Desgranges, Brigitte Landeau, Jean-Claude Baron, Francis Eustache. 2001. Visual Priming Within and Across Symbolic Format Using a Tachistoscopic Picture Identification Task: A PET StudyVisual Priming Within and Across Symbolic Format Using a Tachistoscopic Picture Identification Task: A PET Study. Journal of Cognitive Neuroscience 13:5, 670-686. [Abstract] [PDF] [PDF Plus]

6. Ilan Diamant. 2001. ON NOT BEING ABLE TO KNOW OTHERS' MINDS: THE DEBATE ON RECOVERED MEMORIES OF ABUSE FROM A RELATIONAL PERSPECTIVE. British Journal of Psychotherapy 17:3, 344-352. [CrossRef]

7. Howard Eichenbaum. 1997. DECLARATIVE MEMORY: Insights from Cognitive Neurobiology. Annual Review of Psychology 48:1, 547-572. [CrossRef]

8. Maureen Schmitter-Edgecombe. 1996. The effects of divided attention on implicit and explicit memory performance. Journal of the International Neuropsychological Society 2:02, 111. [CrossRef]

9. MORRIS MOSCOVITCH, GORDON WINOCUR. 1996. Frontal Lobes, Memory, and Aging. Annals of the New York Academy of Sciences 769:1 Structure and, 119-150. [CrossRef]

10. J. G. Taylor, F. N. Alavi. 1995. A global competitive neural network. Biological Cybernetics 72:3, 233-248. [CrossRef]

11. Daniel L. Schacter, Lynn A. Cooper, Jonathan Treadwell. 1993. PRESERVED PRIMING OF NOVEL OBJECTS ACROSS SIZE TRANSFORMATION IN AMNESIC PATIENTS. Psychological Science 4:5, 331-335. [CrossRef]

12. Timothy P. McNamara, Jon B. HolbrookSemantic Memory and Priming . [CrossRef] 